\title{
Contemplated Investigation and Statistical Prediction of the Swelling Potential of Expansive Soils Using Index Properties of Holte Town, Southern Ethiopia
}

\author{
Tilahun K. Entonyos $(\mathbb{D}$, Defaru K. Dasho $\mathbb{D}$, and Vasudeva R. Pampana \\ Civil Engineering, Arba Minch University, P.O. Box. 21, Arba Minch, Ethiopia \\ Correspondence should be addressed to Defaru K. Dasho; defaru.katise@amu.edu.et
}

Received 8 December 2021; Revised 14 January 2022; Accepted 17 January 2022; Published 31 January 2022

Academic Editor: Fujiao Tang

Copyright (c) 2022 Tilahun K. Entonyos et al. This is an open access article distributed under the Creative Commons Attribution License, which permits unrestricted use, distribution, and reproduction in any medium, provided the original work is properly cited.

\begin{abstract}
Expansive soils are problematic by exhibitingl shrink-swell behaviors and high plasticity under different moisture conditions, which is communal in salient areas of Ethiopia. This article aims to conduct a contemplated investigation and statistical analysisbased prediction for swelling potentials of soils using the index properties. This is used to define the properties of soils by investigation and to minimize the rigorous futuristic investigation by providing the prediction model of soils of the Holte town. Hence, thirty soil samples were collected from fifteen test pits with a depth of $1.5 \mathrm{~m}$ to $3.0 \mathrm{~m}$ from various locations. Investigations were conducted in the field and laboratory. Results revealed that the in situ moisture content, dry density, and bulk unit weight ranges were found, $31.21-40.93 \%, 1.20-1.30 \mathrm{~g} / \mathrm{cm}^{3}$, and $1.60-1.73 \mathrm{~g} / \mathrm{cm}^{3}$, respectively. The soil grain results presented that the study area is dominantly fine-grained soil properties (i.e., silt and clay). Liquid limit, plastic limit, plasticity index, and liquidity index ranged from 58 to $77 \%, 26-33 \%, 28-45 \%$, and $0.00-0.35 \%$, respectively, which assured that the soils in this town have $87 \%$ high plastic clay $(\mathrm{CH})$. In addition, the swelling potential, swelling pressure, free swell, and activity investigations revealed that the soils in this town are highly plastic with a high degree of expansiveness. This was found that the swelling potential is the main measuring property of expansive soils, which was predicted by the statistical tool SPSS using numerous index properties. After conducting numerous statistical models, the best swelling potential was found $\mathrm{Sp}=6.876 \gamma_{d}+0.178 \mathrm{PI}-10.664$, which is maintained by $90 \%$ of the points found within the regression line having a mean confidence level of $99.99 \%$. In conclusion, the obtained model was validated and was found as an optimal measuring tool of expansiveness through the swelling potential of soils specifically in Holte town.
\end{abstract}

\section{Introduction}

Foundation materials that perform volume change with moisture within and highly plastic soils are mentioned as expansive soils. These soils are problematic soil that can induce problems on structural and nonstructural parts of building through shrinkage and swelling by moisture variations [1]. This can cause mainly lightly loaded structure built on expansive soils to move differentially, crack, and shows damage due to rough movement caused by swelling and shrinking of the soils. As a result, they are inappropriate for direct engineering purposes in their natural form, and therefore it is needed to investigate and quantify swelling tendencies of these soils, which is essential in the perspectives of the present-day geotechnical engineering practice $[2,3]$. Factors that affect the swelling potential and swelling pressure of expansive soils are the composition of the soil and environmental factors, compositions of the soil factors are liquid limit, plasticity index, and colloidal content, whereas suction pressure, surcharge pressure, in situ dry density, and in situ moisture content are placement factors [4]. Holte town is one of boosting town by different infrastructures in the southern part of Ethiopia. This town is found in arid and semi-arid regions of the country in which expansive soils are commonly deposited [5]. Due to these soils, there was usually damage to the building structures and 
road pavements in the study area. Geotechnical investigations by nature are laborious, time-consuming, and expensive. For instance, the swell-consolidation test for direct measurement of expansive properties is more difficult when compared with a simple index property test. Hence, empirical formulations of swelling parameters of such soils are done in order to determine required behaviors indirectly $[6,7]$. The common soil index behaviors, such as Atterberg's limits, plasticity index, percentage of fines, activity, density, void ratio, water content, soil suction, and degree of saturation, are considerably influencing the swelling behaviours of expansive soils $[8,9]$. Hence, this research is mainly aimed to provide SPSS version 20 statistical prediction of expansive soil behaviours using index properties of Holte town in southern Ethiopia in order to minimize the effort, time, and cost of the investigation. The swelling tendencies of expansive soils are quantified by the swelling parameters, such as swelling potential and swelling pressure. These parameters were determined in the laboratory that expansive soils behave through a one-dimensional oedometer test [10]. The swelling is a very useful index of the troubling potential of expansive soils, but less than $20 \mathrm{kPa}$ may not be regarded as of much consequence in which index properties were used as input to predict soil expansiveness [11]. In soil property investigation and analysis, SPSS version 20 is commonly used as a statistical analysis tool. This tool is used for salient types of analysis such as regression models for required variables from independent parameters. It is a powerful, integrated family of statistical modeling products that assists with the entire analytical process, from planning to deployment. This tool is important and effective to correlate rigorous and time-consuming geotechnical soil parameters from simply tested index properties. Using such tools, predictive analyses are important for geotechnical engineering activities in order to easily determine soil properties [12-15]. This study is significantly important for the communities that are in process of building construction in Holte town. These soil investigations can also be used in future for the better inputs to the predicting model to obtain expansiveness of the soil in the study area. The new futuristic statistical model can also significantly reduce the time, cost, and efforts for a new investigation that are rigorous, time-consuming, and very costly and also requires expensive and complex machines as well to conduct tests on the soils of this area. The main contribution focuses on the contemplated investigation and modeling for the swelling potential. In this concern, the study area has mostly expansive soils and typically lagging behind in scientific investigations. Constructions are also done without considerable scientific investigations and design specifications and hence salient light-weighted buildings are failed or face the problems of the cracks. Holte town is located $547 \mathrm{~km}$ away from the national capital city Addis Abeba and is lagging behind in terms of road conditions, power shortage, skilled human resources, and availability of investigation devices and machines to test the soil properties in the town. Due to all aforementioned factors, this study intended to investigate the soils and to predict the soil behaviors through newly evolved models and mechanisms, particularly the investigation of the soil expansiveness through swelling potential.

\section{Materials and Methods}

2.1. Description of Study Area. Holte town is located in southern nation's nationalities people region (SNNPR) in Ethiopia. This town is located $547 \mathrm{~km}$ south of Addis Ababa, $326 \mathrm{~km}$ south of Hawassa, and $50 \mathrm{~km}$ southwest of Arba Minch. This town also situated on plain landforms is found within the great Ethiopia rift valley and the relief of the town stretches from $1132 \mathrm{~m}$ up to $1169 \mathrm{~m}$ above sea level. The geographical coordinates of the town are falling from $5^{\circ} 38^{\prime} 30^{\prime \prime}-5^{\circ} 40^{\prime} 30^{\prime \prime}$ latitude to $37^{\circ} 26^{\prime} 0^{\prime \prime}-37^{\circ} 29^{\prime} 0^{\prime \prime}$ longitude, as shown in Figure 1. As far as the temperature, climate, and wind are also concerned, the town experiences the mean annual temperature with the range of $15^{\circ} \mathrm{c}$ to $27^{\circ} \mathrm{c}$, which is the "Kole" climate of the country.

2.2. Field and Laboratory Experimentation. This research is focused on the field and laboratory investigations of the expansive soils. The in situ moisture content and bulk unit density were tested in the field, whereas the specific gravity, grain size analysis, Atterberg's limits, free swell, compaction, and consolidation were investigated and analysed in the laboratory based on the American Society for Testing and Materials Procedures. The fifteen test pits were identified as per variation of soils and existing as well as the future expansion plan of this town, as shown in Figure $1(\mathrm{~d}))$. The selected pits were excavated to the most potential zone of expansiveness depth of $1.50 \mathrm{~m}$ to maximum of $3.0 \mathrm{~m}$ to collect two soil samples from each pit to have thirty total samples. The in situ moisture content and density tests were conducted in the field during sample collection process. A sufficient disturbed and undisturbed soil sample sizes from all pits were used for laboratory experimentation and analysis [16].

\subsubsection{In Situ Moisture Content and Density Determination.} In this study, the moisture content (gravimetric moisture) determination was done by the conventional oven in the laboratory based on ASTM procedures. Mass of density specimens was recorded just after sample. Two trial moisture specimens from each test samples were taken and placed to dry them in an oven for 24 hours with a standard temperature of $110^{\circ} \mathrm{C}$ [17]. Then, moisture and densities were analysed and determined.

2.2.2. Soil Grain and Atterberg's Limit Tests. In this phase, the particle size distribution for course soils was conducted applying wet sieving by washing the specimen through $0.075 \mathrm{~mm}$, whereas sedimentation tests for fine fractions were conducted by hydrometer method based on the "Stokes" sedimentation rates [18]. The Atterberg's limit tests were carried out on the soil samples that were oven-dried and finer than $0.425 \mathrm{~mm}$ sieve size. After drying and sieving, the soil samples were weighed and soaked for 30 minutes to maintain full saturation. Then, using Casagrande's apparatus liquid limit test for all collected samples was conducted and results were obtained. The plastic limit tests were carried out 


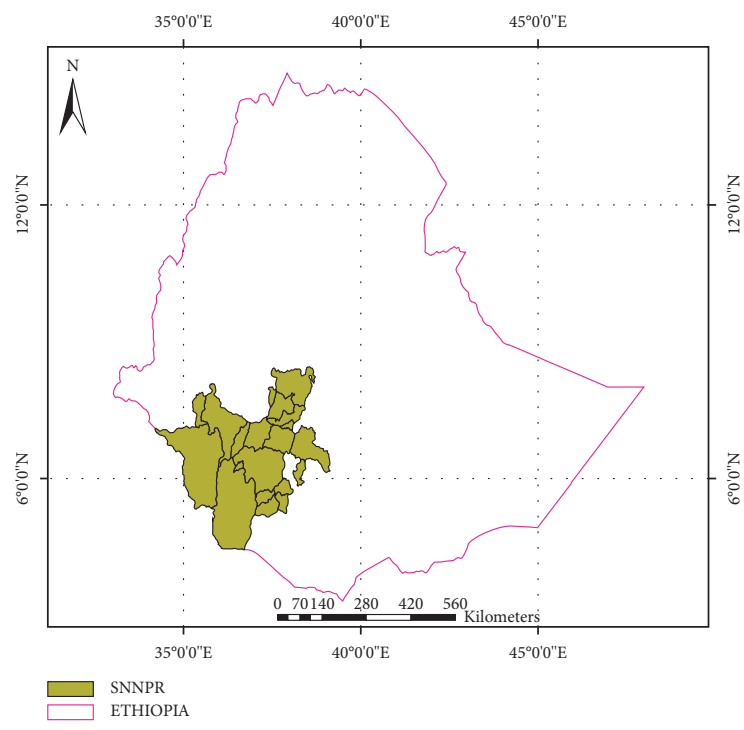

(a)

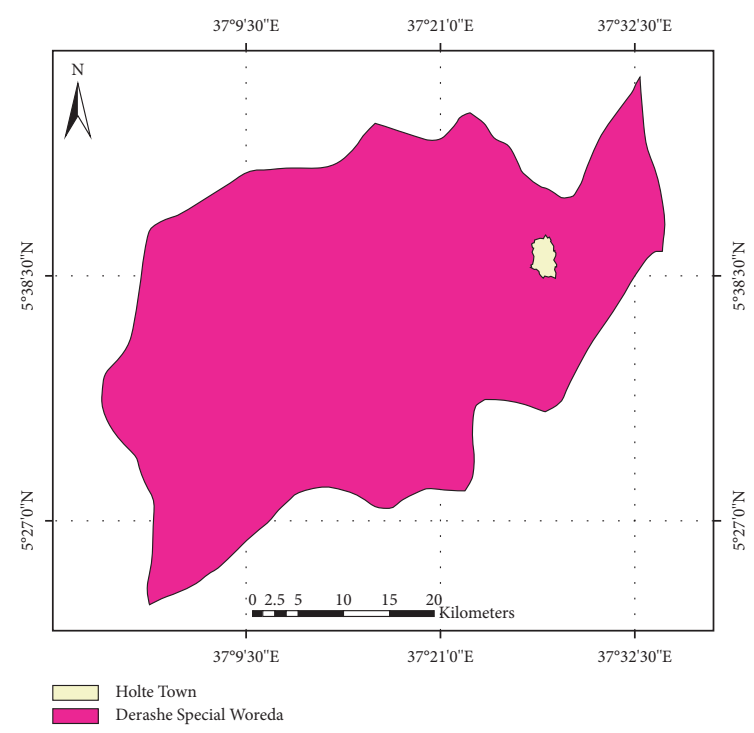

(c)

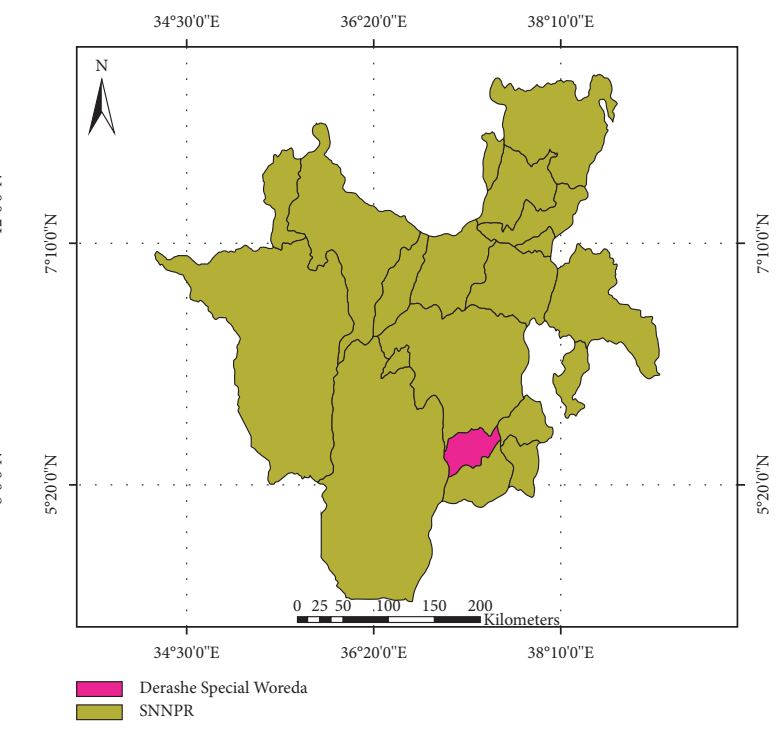

(b)

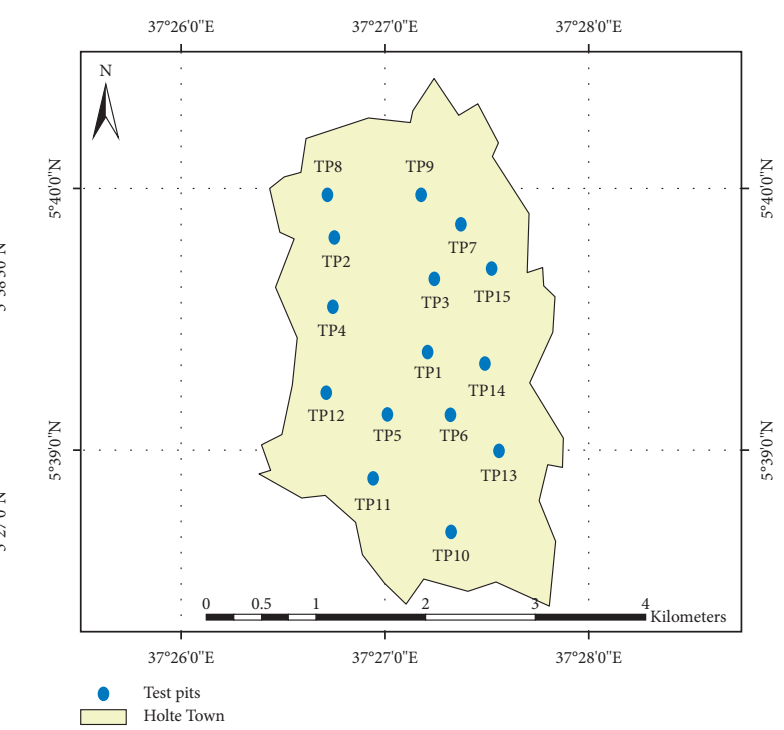

(d)

Figure 1: Map of (a) Ethiopia, (b) map of SNNPR, (c) Holte town, and (d) test pit location.

by taking soil specimens from thoroughly wetted and mixed liquid limit soil samples. It was found that the water evaporates and the water content decreases until the tread splits and crumbles at $3 \mathrm{~mm}$ diameter thread. These plastic limit specimens were placed in an oven for 24 hours to determine moisture content termed as plastic limit. As a matter of practicable facts, three trials tests were conducted and the average moisture content was considered for plastic limit [19]. Finally, the soil grain tests and Atterberg's limit tests were used to classify the numerous soils.

2.2.3. Specific Gravity. As a matter of fact, the specific gravity is defined as the ratio of the mass of a unit volume of the soil solids to the mass of the same volume of gas-filled by distilled water at the standard temperature of $20^{\circ} \mathrm{c}$. In this study, the specific gravity of fine-grained soil solids in the laboratory was carried out by a Pycnometer method in which the wet specimens dispersed in distilled water before they are placed in the pycnometer by using dispersing equipment specified in the standard test procedure for a grain size of soils [20]. Two trial specific gravity tests were done and averaged in this study to have reliable results.

2.2.4. Soil Moisture-Density Relationship Test. In this test, the compaction tests were conducted for the determination of the maximum dry density and optimum moisture content from moisture-density relationships of the soils. To obtain these properties, the oven dried soil samples were separately prepared for each trial tests and compacted by the standard efforts of 25 blows per every three layers. The trial tests were continued by increasing and decreasing mixing moisture up to mass of compacted soil specimen reduced, which was 
observed that the density of compacted specimens increases initially up to optimum moisture and then decreases. For the optimal results, at least four trial tests were conducted on a single test pit, and moisture-density curve was plotted to identify the optimum moisture and maximum density of soils in Holte town [21].

\subsubsection{One-Dimensional Oedometer Test. A consolidation} test was carried out in the laboratory using one-dimensional oedometer apparatus that the compression was controlled through the rate at which water is squeezed out of the pores, which is a stress-strain-time phenomenon. The axial stress was provided by adding or removing weights and therefore the loading was stress controlled and applied in stages or varied smoothly in continuous loading tests from which the axial strain is measured by using dial gauges. Accordingly, the soil samples were placed on a consolidation ring of $63 \mathrm{~mm}$ sample diameter and $20 \mathrm{~mm}$ sample height. Porous discs at the top and bottom were used to act as a drain and so that the seepage of pore water is found vertical and one dimensional. To determine the swelling potential and the swelling pressure, loading pressures applied were $7 \mathrm{kPa}$, $50 \mathrm{kPa}, 100 \mathrm{kPa}, 200 \mathrm{kPa}, 400 \mathrm{kPa}, 800 \mathrm{kPa}$, and $1600 \mathrm{kPa}$, whereas the unloading pressures were $1600 \mathrm{kPa}, 400 \mathrm{kPa}$, $100 \mathrm{kPa}$, and $7 \mathrm{kPa}$, and test result reading was taken at 0.25 , $0.5,1,2,4,8,15,30$ minutes, $1,2,4,8,24$ hours. In this study, the swelling potential and swelling pressure of soil in the laboratory were carried out by conventional oedometer test [22]. Tests were performed with varying initial conditions of molding water content and dry density, which exhibited a unique correlation between swelling pressure and the initial dry density for swelling soils [23].

Free swell tests were also used to evaluate the soil's expansiveness, which was carried out for the volume of settled and swelled read after 24 hours from the graduated cylinder to determine free swell as the ratio expression of the percentage of final volume minus its initial volume to its initial volume. This concludes that the soils having a free swell of $100 \%$ or more can damage the lightly loaded structures, whereas less than $50 \%$ do not pose serious problems to the structures [24].

\subsection{Regression Analysis for Prediction of Swelling Potential.} The swelling pressure and swelling potential properties can be directly obtained in the laboratory from oedometer tests or indirect correlation from the index properties of the soils. This is hence this study was focused on the contemplated investigation that measure directly, and statistical model was maintained for indirect measurement of expansive soils. Most of the mathematical models are based on plasticity index, Atterberg's limits, and clay contents conversely, the method disregards the in situ conditions of soil, such as its field density and the initial water content [25]. In this experimental analysis phase, the SPSS 20 was used to predict the futuristic swelling potential of expansive soils from index properties. To predict a new or futuristic observation of swelling potential in this paper, the study carried out a single and multiple linear regression analysis. Accordingly, swelling potential responses as a dependent variable and plasticity index, liquid limit, plastic limit, percentage finer than $0.002 \mathrm{~mm}$, liquidity index, percentage finer than $0.075 \mathrm{~mm}$, in situ density, and in situ moisture content were used as predictor variables in this statistical tool [26, 27]. R-square provides the percentage variation of response variables and is explained by the predictor variables. Accordingly, the simple linear regression is a straight analysis with one variable, or dependent variable is a function of independent variable, but multiple linear regressions are more than one predictor variable in this article $[28,29]$. In conclusion, the performance of the multiple statistical models was selected in this study, and analysis was mainly found dependent on the size of the data set. Therefore, this study incorporated thirty soil samples property data sets that were used to characterize and increase input data to find out the formulas that are good fitting for expansive behaviours of soils at any condition specifically for Holte town.

\section{Results and Discussion}

3.1. Field and Laboratory Test Results. The in situ tests for moisture content, bulk unit weight, and dry density of the study area range from 31.21 to $40.93 \%, 1.60$ to $1.73 \mathrm{~g} / \mathrm{cm}^{3}$, and 1.20 to $1.30 \mathrm{~g} / \mathrm{cm}^{3}$, with the average of $35.63 \%, 1.69 \mathrm{~g} / \mathrm{cm}^{3}$, and $1.24 \mathrm{~g} / \mathrm{cm}^{3}$, respectively, are shown in Table 1 . As the depth of the soil layer increases, the moisture content increases while the dry density decreases. This indicates that the swelling deformation of studied soil is nonlinear with the depth of soil layer and apparent difference between an upper and lower layer of the study area, i.e., Holte town [30].

3.1.1. Grain Size Analysis Results and Discussion. As presented in Figure 2, the grain size analysis test results of the study area of gravel range from $0 \%$ to $2 \%$, sand ranges from $1 \%$ to $6 \%$, silt ranges from $36 \%$ to $49 \%$, clay ranges from $47 \%$ to $59 \%$ with the percentage finer than $0.075 \mathrm{~mm}$ ranges from 92 to $98 \%$. The results convinced that the study area is dominantly fine-grained soil so called silt and clay with the average of $1 \%$ gravel, $3 \%$ sand, $43 \%$ silt, and $53 \%$ of clay in the Holte town.

The study area is also characterized by the specific gravity varying from 2.66 to $2.75 \mathrm{~g} / \mathrm{cm}^{3}$, which was described as finegrained soil category (as shown in Table 2). The dominance of clay soils or higher fractions of clay content revealed the high plasticity behavior of soils.

3.1.2. Atterberg's Limit Results. The Atterberg's limits such as liquid limit ranges from 58 to $77 \%$, plastic limit ranges from 26 to $33 \%$, plasticity index ranges from 28 to $45 \%$, and the liquidity index ranges from 0.0 to $0.35 \%$ of the study area. The average values of the liquid limit, plastic limit, plasticity index, and liquidity index were found 69\%, 29\%, $40 \%$, and $0.17 \%$, respectively. Based on these liquidity index results, the soil state falls in plastic state category, as shown in Table 2. This implies that the soil of this study area deforms like plastic material. 
TABLe 1: Test pit locations and in situ test results.

\begin{tabular}{|c|c|c|c|c|c|c|}
\hline Test pits & Longitude & Latitude & Depth $(\mathrm{m})$ & Bulk density $\left(\mathrm{g} / \mathrm{cm}^{3}\right)$ & $\mathrm{w}(\%)$ & In situ dry density $\left(\mathrm{g} / \mathrm{cm}^{3}\right)$ \\
\hline \multirow{2}{*}{ TP1 } & \multirow{2}{*}{$37^{\circ} 27^{\prime} 13.03^{\prime \prime} \mathrm{E}$} & \multirow{2}{*}{$5^{\circ} 39^{\prime} 22.30^{\prime \prime} \mathrm{N}$} & 1.5 & 1.66 & 33.47 & 1.24 \\
\hline & & & 3.0 & 1.69 & 37.57 & 1.23 \\
\hline \multirow{2}{*}{ TP2 } & \multirow{2}{*}{$37^{\circ} 26^{\prime} 55.05^{\prime \prime} \mathrm{E}$} & \multirow{2}{*}{$5^{\circ} 39^{\prime} 5832^{\prime \prime} \mathrm{N}$} & 1.5 & 1.72 & 33.63 & 1.29 \\
\hline & & & 2.5 & 1.68 & 39.35 & 1.21 \\
\hline \multirow{2}{*}{ TP3 } & \multirow{2}{*}{$37^{\circ} 27^{\prime} 14.58^{\prime \prime} \mathrm{E}$} & \multirow{2}{*}{$5^{\circ} 39^{\prime} 39.26^{\prime \prime} \mathrm{N}$} & 1.5 & 1.71 & 31.21 & 1.30 \\
\hline & & & 2.5 & 1.71 & 37.93 & 1.24 \\
\hline \multirow{2}{*}{ TP4 } & \multirow{2}{*}{$37^{\circ} 26^{\prime} 56.66^{\prime \prime} \mathrm{E}$} & \multirow{2}{*}{$5^{\circ} 39^{\prime} 32.88^{\prime \prime} \mathrm{N}$} & 1.5 & 1.70 & 32.80 & 1.28 \\
\hline & & & 2.5 & 1.71 & 40.40 & 1.22 \\
\hline \multirow{2}{*}{ TP5 } & \multirow{2}{*}{$37^{\circ} 27^{\prime} 0.87^{\prime \prime} \mathrm{E}$} & \multirow{2}{*}{$5^{\circ} 39^{\prime} 8.20^{\prime \prime} \mathrm{N}$} & 1.5 & 1.66 & 31.68 & 1.26 \\
\hline & & & 2.2 & 1.70 & 39.44 & 1.22 \\
\hline \multirow{2}{*}{ TP6 } & \multirow{2}{*}{$37^{\circ} 27^{\prime} 19.34^{\prime \prime} \mathrm{E}$} & \multirow{2}{*}{$5^{\circ} 39^{\prime} 7.99^{\prime \prime} \mathrm{N}$} & 1.5 & 1.65 & 33.42 & 1.24 \\
\hline & & & 2.0 & 1.70 & 37.94 & 1.23 \\
\hline \multirow{2}{*}{ TP7 } & \multirow{2}{*}{$37^{\circ} 27^{\prime} 22.30^{\prime \prime} \mathrm{E}$} & \multirow{2}{*}{$5^{\circ} 39^{\prime} 51.74^{\prime \prime} \mathrm{N}$} & 1.5 & 1.71 & 31.58 & 1.30 \\
\hline & & & 2.25 & 1.68 & 39.51 & 1.21 \\
\hline \multirow{2}{*}{ TP8 } & \multirow{2}{*}{$37^{\circ} 26^{\prime} 56.93^{\prime \prime} \mathrm{E}$} & \multirow{2}{*}{$5^{\circ} 39^{\prime} 48.64^{\prime \prime} \mathrm{N}$} & 1.5 & 1.71 & 31.71 & 1.30 \\
\hline & & & 2.2 & 1.73 & 40.93 & 1.23 \\
\hline \multirow{2}{*}{ ТP9 } & \multirow{2}{*}{$37^{\circ} 27^{\prime} 10.71^{\prime \prime} \mathrm{E}$} & \multirow{2}{*}{$5^{\circ} 39^{\prime} 58.50^{\prime \prime} \mathrm{N}$} & 1.5 & 1.72 & 32.26 & 1.30 \\
\hline & & & 2.2 & 1.70 & 40.73 & 1.21 \\
\hline \multirow{2}{*}{ TP10 } & \multirow{2}{*}{$37^{\circ} 27^{\prime} 9.86^{\prime \prime} \mathrm{E}$} & \multirow{2}{*}{$5^{\circ} 39^{\prime} 55.91^{\prime \prime} \mathrm{N}$} & 1.5 & 1.68 & 35.18 & 1.24 \\
\hline & & & 2.0 & 1.67 & 36.99 & 1.22 \\
\hline TP11 & & $5^{\circ} 38^{\prime} 5328^{\prime \prime} \mathrm{N}$ & 1.5 & 1.60 & 32.56 & 1.20 \\
\hline IP11 & $3726^{\circ} 56.40^{\circ} \mathrm{E}$ & $53853.28 \mathrm{~N}$ & 2.5 & 1.69 & 37.23 & 1.23 \\
\hline & & & 1.5 & 1.66 & 31.98 & 1.26 \\
\hline TP12 & $3 / 2642.63^{\circ} \mathrm{E}$ & $539^{\circ} 13.12^{2} \mathrm{~N}$ & 3.0 & 1.67 & 39.5 & 1.20 \\
\hline TP13 & $37^{\circ} 27^{\prime} 33.55^{\prime \prime} \mathrm{E}$ & & 1.5 & 1.63 & 34.01 & 1.22 \\
\hline $1 P 13$ & $3 / 2733.55 \mathrm{E}$ & $538^{\circ} 59.59^{\circ} \mathrm{N}$ & 2.0 & 1.66 & 36.83 & 1.21 \\
\hline TP14 & $37^{\circ} 27^{\prime} 31.49^{\prime \prime} \mathrm{E}$ & $5^{\circ} 39^{\prime} 19.76^{\prime \prime} \mathrm{N}$ & 1.5 & 1.66 & 32.97 & 1.25 \\
\hline & & & 2.5 & 1.70 & 36.74 & 1.24 \\
\hline TP15 & $37^{\circ} 27^{\prime} 31.34^{\prime \prime} \mathrm{E}$ & $5^{\circ} 39^{\prime} 41.51^{\prime \prime} \mathrm{N}$ & 1.5 & 1.71 & 31.33 & 1.30 \\
\hline $1 P 15$ & $3 / 2 / 31.34 \mathrm{E}$ & $53941.51 \mathrm{~N}$ & 3.0 & 1.73 & 38.00 & 1.25 \\
\hline
\end{tabular}

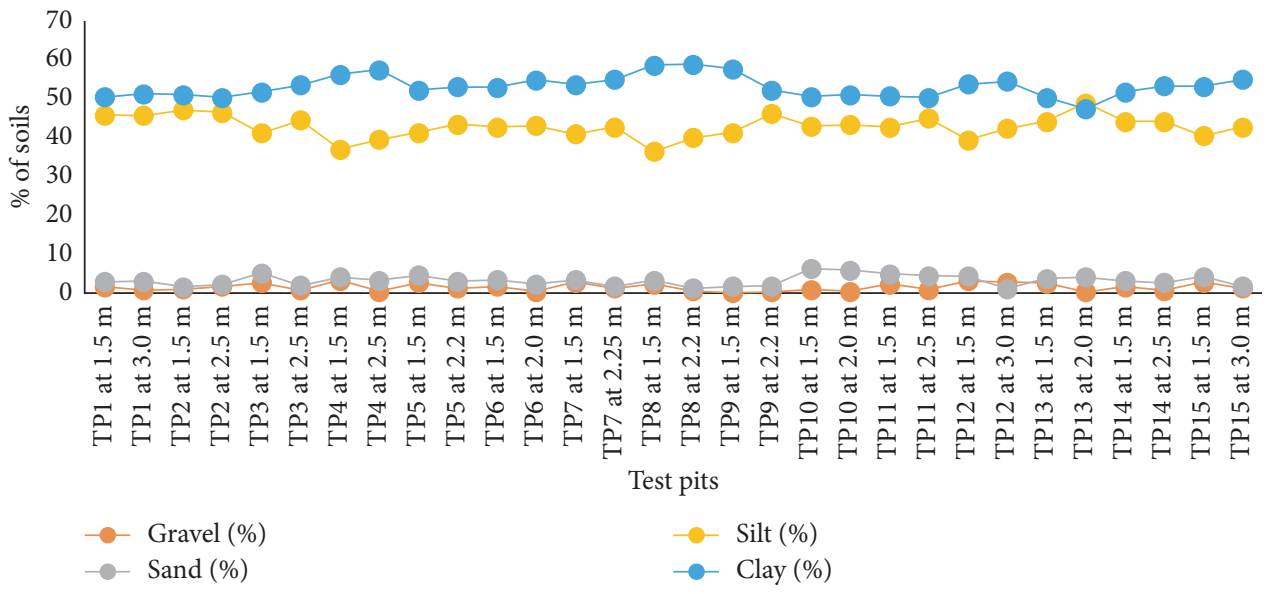

Figure 2: Percentage of gravel, sand, silt, and clay of the study area.

3.1.3. Soil Classifications. According to the test results indicated in soil grain analysis and Atterberg's limit tests, the study area falls under A-7-5 and A-7-6 group of silt-clay materials with high clay constituent based on AASHTO soil classification. These soil classes are rated as poor subgrade material for road pavement construction. Thereby more than twenty group indexes indicated that the area was accumulated by the high plasticity indexed expansive soils, which revealed the considerable high volume of changes in soil materials, as shown in Table 2 . Whereas the study area falls under inorganic clays of high plastic clay soil except the test pits TP10 and TP11, which is inorganic silt (MH) as per 
TABLE 2: AASHTO and USCS classification, Atterberg's limits test results.

\begin{tabular}{|c|c|c|c|c|c|c|c|c|}
\hline \multirow{2}{*}{ Test pits } & \multirow{2}{*}{ Depth $(\mathrm{m})$} & \multirow{2}{*}{ Specific gravity, Gs $\left(\mathrm{g} / \mathrm{cm}^{3}\right)$} & \multicolumn{3}{|c|}{ Atterberg's limits tests } & \multicolumn{2}{|c|}{ Soil classification } & \multirow{2}{*}{ Swelling potential } \\
\hline & & & LL (\%) & PI (\%) & LI (\%) & AASHTO & USCS & \\
\hline \multirow{2}{*}{ TP1 } & 1.5 & 2.7 & 65 & 39 & 0.19 & A-7-6(43) & $\mathrm{CH}$ & High \\
\hline & 3.0 & 2.71 & 65 & 39 & 0.31 & A-7-6(43) & $\mathrm{CH}$ & High \\
\hline \multirow{2}{*}{$\mathrm{TP} 2$} & 1.5 & 2.68 & 67 & 39 & 0.15 & A-7-6(45) & $\mathrm{CH}$ & High \\
\hline & 2.5 & 2.74 & 64 & 38 & 0.35 & A-7-6(42) & $\mathrm{CH}$ & High \\
\hline \multirow{2}{*}{ TP3 } & 1.5 & 2.69 & 69 & 42 & 0.09 & A-7-6(44) & $\mathrm{CH}$ & High \\
\hline & 2.5 & 2.74 & 67 & 41 & 0.28 & A-7-6(46) & $\mathrm{CH}$ & High \\
\hline \multirow{2}{*}{$\mathrm{TP} 4$} & 1.5 & 2.68 & 77 & 44 & 0.01 & A-7-5(49) & $\mathrm{CH}$ & High \\
\hline & 2.5 & 2.73 & 71 & 43 & 0.28 & A-7-6(48) & $\mathrm{CH}$ & High \\
\hline \multirow{2}{*}{ TP5 } & 1.5 & 2.68 & 75 & 43 & 0 & A-7-5(48) & $\mathrm{CH}$ & High \\
\hline & 2.2 & 2.7 & 70 & 39 & 0.23 & A-7-5(45) & $\mathrm{CH}$ & High \\
\hline \multirow{2}{*}{ TP6 } & 1.5 & 2.72 & 77 & 45 & 0.02 & A-7-5(51) & $\mathrm{CH}$ & High \\
\hline & 2.0 & 2.73 & 68 & 42 & 0.28 & A-7-6(47) & $\mathrm{CH}$ & High \\
\hline \multirow{2}{*}{ TP7 } & 1.5 & 2.71 & 76 & 44 & 0 & A-7-5(49) & $\mathrm{CH}$ & High \\
\hline & 2.25 & 2.75 & 75 & 42 & 0.16 & A-7-5(49) & $\mathrm{CH}$ & High \\
\hline \multirow{2}{*}{ TP8 } & 1.5 & 2.71 & 76 & 45 & 0.03 & A-7-5(50) & $\mathrm{CH}$ & High \\
\hline & 2.2 & 2.74 & 72 & 44 & 0.29 & A-7-6(51) & $\mathrm{CH}$ & High \\
\hline \multirow{2}{*}{ TP9 } & 1.5 & 2.69 & 76 & 44 & 0.01 & A-7-5(53) & $\mathrm{CH}$ & High \\
\hline & 2.2 & 2.75 & 69 & 39 & 0.28 & A-7-6(46) & $\mathrm{CH}$ & High \\
\hline \multirow{2}{*}{ TP10 } & 1.5 & 2.69 & 60 & 29 & 0.12 & A-7-5(32) & $\mathrm{MH}$ & High \\
\hline & 2.0 & 2.66 & 58 & 28 & 0.23 & A-7-5(31) & $\mathrm{MH}$ & High \\
\hline \multirow{2}{*}{$\mathrm{TP} 11$} & 1.5 & 2.68 & 64 & 32 & 0.06 & A-7-5(36) & $\mathrm{MH}$ & High \\
\hline & 2.5 & 2.69 & 59 & 28 & 0.22 & A-7-5(32) & $\mathrm{MH}$ & High \\
\hline \multirow{2}{*}{ TP12 } & 1.5 & 2.68 & 75 & 44 & 0.04 & A-7-5(48) & $\mathrm{CH}$ & High \\
\hline & 3.0 & 2.71 & 68 & 41 & 0.31 & A-7-6(46) & $\mathrm{CH}$ & High \\
\hline \multirow{2}{*}{ TP13 } & 1.5 & 2.7 & 67 & 37 & 0.11 & A-7-5(41) & $\mathrm{CH}$ & High \\
\hline & 2.0 & 2.72 & 61 & 36 & 0.31 & A-7-6(39) & $\mathrm{CH}$ & High \\
\hline \multirow{2}{*}{ TP14 } & 1.5 & 2.68 & 70 & 41 & 0.1 & A-7-6(46) & $\mathrm{CH}$ & High \\
\hline & 2.5 & 2.71 & 66 & 40 & 0.27 & A-7-5(45) & $\mathrm{CH}$ & High \\
\hline \multirow{2}{*}{ TP15 } & 1.5 & 2.69 & 71 & 45 & 0.1 & A-7-6(48) & $\mathrm{CH}$ & High \\
\hline & 3.0 & 2.73 & 69 & 41 & 0.26 & A-7-6(47) & $\mathrm{CH}$ & High \\
\hline
\end{tabular}

Unified Soil Classification System. In which all test pits having liquid limits values more than fifty revealed that the soils in the area are presented by high plasticity and expansiveness, which are fulfilling the requirements of the specified practices of expansive properties [31].

3.1.4. Moisture-Density Relationship. The standard compaction test results of the study area for maximum dry density (MDD) ranges from 1.22 to $1.33 \mathrm{~g} / \mathrm{cm}^{3}$ and optimum moisture content (OMC) ranges from 27.42 to $35.5 \%$ are shown in Table 3 . The average value of maximum dry density (MDD) is $1.26 \mathrm{~g} / \mathrm{cm}^{3}$, and the average value of OMC is $31.72 \%$, which presents the properties of weak clay soils like expansive soils of the Holte town [32].

3.1.5. Swelling Properties of Expansive Soils. The consolidated test results of the study for the swelling potential range from 2.40 to $6.73 \%$, swelling pressure from 40 to $180 \mathrm{kPa}$, and free swell from 70 to $105 \%$ are found. The average value of the study area for swelling potential found was $4.98 \%$, for swelling pressure $103.03 \mathrm{kPa}$, and the average value of free swell $91.83 \%$, as shown in Table 3 .
As indicated in Figure 3(a)) on activity chart plot, the results of the activity of the study area are mostly normal clay soil types that the activity values ranging from 0.55 to 0.85 .

Evaluation of the Swell potential was done as presented in Figure 3(b)) and assured that the study area falls under high potential expansiveness based on their activity and percentage of clay fractions based on swelling potential chart [33].

3.2. Development of Regression Analyses for Swelling Potential. Based on the laboratory test results, it was concluded that the swelling potential is dependent on the soil composition and properties (i.e., index properties) such as liquid limit, plastic limit, plasticity index, percent finer than $0.002 \mathrm{~mm}$, percent finer than $0.075 \mathrm{~mm}$, and liquidity index. The environmental conditions like in situ moisture content and field density of the study area also influenced the swelling behaviour of soils. Hence, swelling potential was taken as dependent soil property and predicted from stated soil factors such as index behaviours of expansive soils. The number of coefficients was considered in this predictive statistical analysis, in which the smallest number of coefficients helped to decide which is the best fit and accurate for the analysis, i.e., the number of 
TABLE 3: Compaction properties and activity and swelling characteristics test results.

\begin{tabular}{|c|c|c|c|c|c|c|c|}
\hline \multirow{2}{*}{ Test pits } & \multirow{2}{*}{ Depth $(\mathrm{m})$} & \multicolumn{2}{|c|}{ Compaction } & \multirow{2}{*}{ Activity, Ac } & \multirow{2}{*}{ Free swell, Fs (\%) } & \multirow{2}{*}{ Swelling potential, $\mathrm{Sp}(\mathrm{kPa})$} & \multirow{2}{*}{ Ps $(\mathrm{kPa})$} \\
\hline & & $\operatorname{MDD}\left(\mathrm{g} / \mathrm{cm}^{3}\right)$ & OMC (\%) & & & & \\
\hline \multirow{2}{*}{ TP1 } & 1.50 & 1.26 & 29.92 & 0.78 & 85 & 4.70 & 90 \\
\hline & 3.00 & 1.25 & 34.78 & 0.77 & 80 & 4.60 & 85 \\
\hline \multirow{2}{*}{ TP2 } & 1.50 & 1.31 & 31.58 & 0.77 & 100 & 5.81 & 150 \\
\hline & 2.50 & 1.22 & 34.56 & 0.76 & 75 & 4.74 & 40 \\
\hline \multirow{2}{*}{ TP3 } & 1.50 & 1.32 & 29.69 & 0.81 & 105 & 6.03 & 180 \\
\hline & 2.50 & 1.26 & 32.84 & 0.76 & 100 & 5.70 & 100 \\
\hline \multirow{2}{*}{$\mathrm{TP} 4$} & 1.50 & 1.29 & 29.30 & 0.79 & 105 & 5.82 & 100 \\
\hline & 2.50 & 1.23 & 33.02 & 0.75 & 85 & 4.90 & 95 \\
\hline \multirow{2}{*}{ TP5 } & 1.50 & 1.28 & 27.46 & 0.83 & 85 & 4.93 & 98 \\
\hline & 2.20 & 1.24 & 35.48 & 0.75 & 80 & 4.89 & 90 \\
\hline \multirow{2}{*}{ TP6 } & 1.50 & 1.26 & 31.06 & 0.85 & 105 & 5.74 & 150 \\
\hline & 2.00 & 1.25 & 34.31 & 0.76 & 100 & 5.65 & 120 \\
\hline \multirow{2}{*}{ TP7 } & 1.50 & 1.33 & 28.79 & 0.83 & 100 & 5.41 & 100 \\
\hline & 2.25 & 1.22 & 35.50 & 0.76 & 90 & 4.91 & 95 \\
\hline \multirow{2}{*}{ TP8 } & 1.50 & 1.32 & 31.97 & 0.77 & 100 & 6.05 & 130 \\
\hline & 2.20 & 1.25 & 32.00 & 0.75 & 95 & 5.88 & 110 \\
\hline \multirow{2}{*}{ TP9 } & 1.50 & 1.30 & 30.00 & 0.77 & 100 & 6.73 & 130 \\
\hline & 2.20 & 1.22 & 34.88 & 0.75 & 90 & 4.78 & 90 \\
\hline \multirow{2}{*}{ TP10 } & 1.50 & 1.26 & 29.55 & 0.57 & 75 & 2.90 & 70 \\
\hline & 2.00 & 1.24 & 31.97 & 0.55 & 70 & 2.40 & 50 \\
\hline \multirow{2}{*}{ TP11 } & 1.50 & 1.23 & 27.85 & 0.67 & 85 & 3.42 & 75 \\
\hline & 2.50 & 1.22 & 32.28 & 0.56 & 80 & 2.61 & 65 \\
\hline \multirow{2}{*}{ TP12 } & 1.50 & 1.25 & 27.42 & 0.83 & 105 & 5.70 & 110 \\
\hline & 3.00 & 1.23 & 35.01 & 0.76 & 95 & 5.00 & 95 \\
\hline \multirow{2}{*}{ TP13 } & 1.50 & 1.24 & 30.10 & 0.75 & 90 & 4.29 & 94 \\
\hline & 2.00 & 1.24 & 32.00 & 0.76 & 85 & 3.81 & 80 \\
\hline \multirow{2}{*}{ TP14 } & 1.50 & 1.27 & 31.35 & 0.80 & 100 & 5.32 & 115 \\
\hline & 2.50 & 1.25 & 34.87 & 0.75 & 90 & 5.00 & 104 \\
\hline \multirow{2}{*}{ TP15 } & 1.50 & 1.31 & 28.79 & 0.84 & 105 & 6.30 & 160 \\
\hline & 3.00 & 1.27 & 33.24 & 0.75 & 95 & 5.28 & 120 \\
\hline
\end{tabular}

independent soil properties involved in the numerous models. It was accepted that it should be less, and the statistical model should give approximately the same swelling potential values compared with measured laboratory results. Table 4 shows the obtained mathematical analysis in multiple regression analysis (MLR) of the study area by using statistical package. The actual pattern of relationships of the swelling potential to input variables (like in situ dry density and plasticity) is more linearly related, which was tested through varied linear trial tests for this research soil. This was initially done before modeling multiple linear analyses and decided to consider multiple linear equations. Accordingly, plasticity index and in situ dry density were found the best predictors in the analysis developed with $90 \%$ of the results fallen within regression line or $R^{2}$ of 0.90 , hypothesis testing probability value ( $P$ value) of 0.00167 , and a mean confidence level (CL) of 99.99\%. The optimal swelling potential $(\mathrm{Sp})$ predicting equation contained the coefficients of in situ dry density $(+6.876)$ and plasticity index $(+0.178)$, which indicated that the increase in dry density and plasticity index leads to an increase in the swelling potential that its result was balanced by constant/Sp intercept $(-10.664)$.
3.2.1. Validity of Developed Statistical Model. The validity of developed statistical analysis model is based on swelling pressure that was selected for control test (Figure 4). This swelling pressure was conducted simultaneously in consolidation test in the laboratory, and swelling potential was determined and analytically obtained $0.027 \mathrm{Ps}+2.235$ with $R^{2}$ of $59.5 \%$. This was done with swelling pressure determined in the laboratory and $0.32 \%$ variation which observed that this variation can be uncontrolled factors such as testing and sampling. During the actual, swelling potential measured and their values are analysed. The approximation points are found nearby the line of equality indicating good prediction and some points are slightly dispersed away from the line of equality. These results indicate that there is a good agreement between the measured and predicted swelling potential values, and this has proved that the validity of the developed statistical equations and their variation, as shown in Figures 5(a) and 5(b)), is acceptable for expansive soils of Holte town of southern Ethiopia.

The suitability of the developed predictive model was also evaluated, and it indicated that the variation of the newly model is $0.32 \%$ from the actually investigated swelling potential, as shown in Figure 5(a). This clearly indicates that 


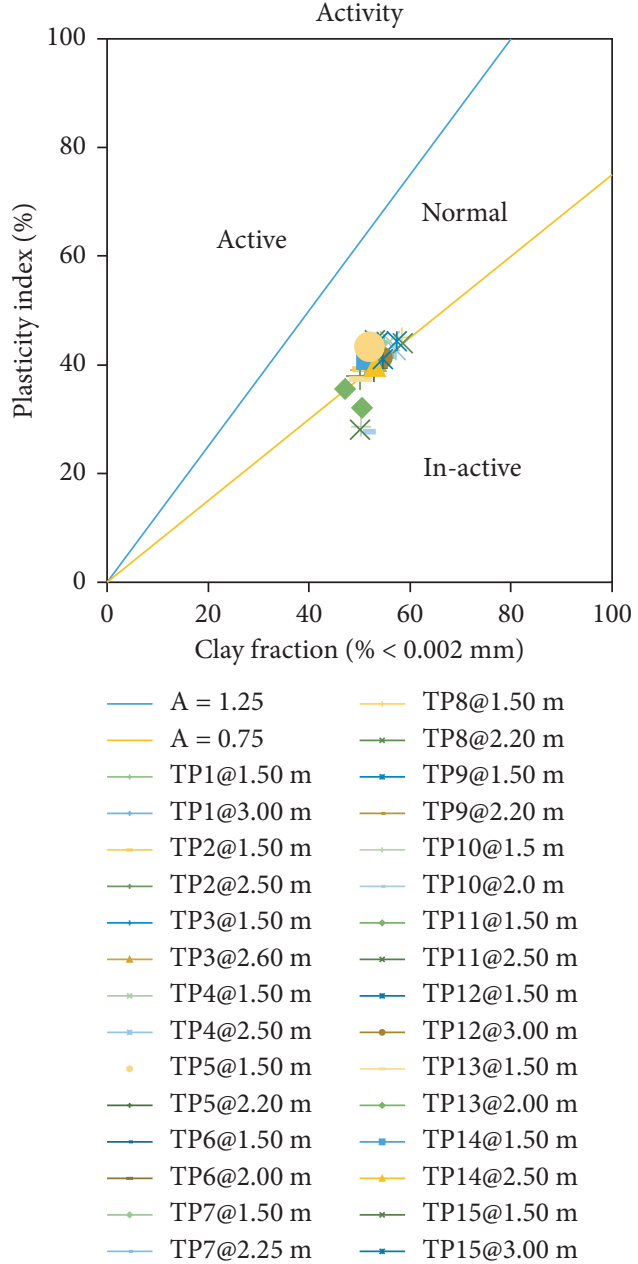

(a)
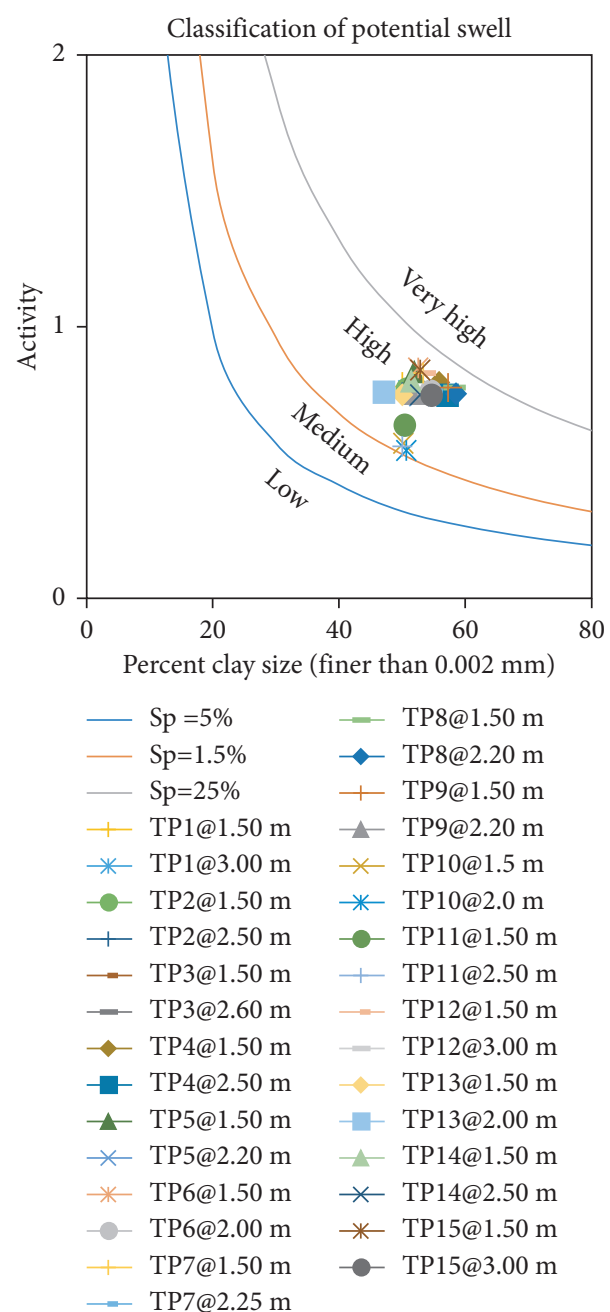

(b)

Figure 3: (a) Activities of clay soil and (b) expansiveness of clay soil by swelling potential.

TABLE 4: Multiple regression analysis for swelling potential, Sp with SPSS.

\begin{tabular}{|c|c|c|c|c|c|c|}
\hline Equations & $\mathrm{r}$ & $R^{2}$ & Adj. $R^{2}$ & Std. error & $P$ value & CL (\%) \\
\hline $\mathrm{Sp}=9.197 \gamma_{d}+0.129 \mathrm{LL}-15.342$ & 0.830 & 0.689 & 0.666 & 0.6156 & 0.0110 & 98.9 \\
\hline $\mathrm{Sp}=6.876 \gamma_{d}+0.178 \mathrm{PI}-10.664$ & 0.949 & 0.900 & 0.892 & 0.3497 & 0.00167 & 99.99 \\
\hline$S p=0.001 w+0.158 L L-5.917$ & 0.794 & 0.630 & 0.602 & 0.6719 & 0.0339 & 66.10 \\
\hline $\mathrm{Sp}=-0.024 w+0.197 \mathrm{PI}-1.988$ & 0.933 & 0.871 & 0.861 & 0.3969 & 0.1280 & 87.20 \\
\hline$S p=0.199 P I+0.005 C-3.199$ & 0.930 & 0.866 & 0.856 & 0.4049 & 0.4655 & 53.45 \\
\hline $\mathrm{Sp}=15.1326 \gamma_{d}+0.82 \mathrm{C}-23.462$ & 0.758 & 0.574 & 0.543 & 0.7208 & 0.0013 & 99.99 \\
\hline $\mathrm{Sp}=23.7696 \gamma_{d}+0.249 \% \mathrm{P}_{200}-48.281$ & 0.748 & 0.560 & 0.527 & 0.7328 & 0.001 & 99.99 \\
\hline $\mathrm{Sp}=9.7888 \gamma_{d}+0.161 \mathrm{PI}+0.109 \% \mathrm{P}_{200}-24.014$ & 0.964 & 0.930 & 0.922 & 0.2979 & 0.0005 & 99.95 \\
\hline $\mathrm{Sp}=7.771 \gamma_{d}+0.229 \mathrm{PI}-0.005 \mathrm{LL}-9.984$ & 0.956 & 0.915 & 0.905 & 0.3286 & 0.0106 & 98.94 \\
\hline $\mathrm{Sp}=6.876 \gamma_{d}+0.176 \mathrm{PI}-0.005 \mathrm{C}-10.887$ & 0.949 & 0.900 & 0.888 & 0.3562 & 0.2193 & 78.07 \\
\hline $\mathrm{Sp}=10.098 \gamma_{d}+0.177 \mathrm{PI}+1.401 \mathrm{LI}-14.847$ & 0.956 & 0.914 & 0.904 & 0.3296 & 0.0118 & 98.82 \\
\hline $\mathrm{Sp}=15.988 \gamma_{d}-0.136 \mathrm{PL}+0.202 \mathrm{C}-21.588$ & 0.816 & 0.665 & 0.627 & 0.6512 & 0.0033 & 99.67 \\
\hline$S p=0.02 C+0.189 P I-0.28 w-2.574$ & 0.934 & 0.872 & 0.857 & 0.4024 & 0.2483 & 75.17 \\
\hline $\mathrm{Sp}=9.89 \gamma_{d}+0.193 \mathrm{PI}+0.094 \% \mathrm{P}_{200}-0.032 \mathrm{LL}-21.734$ & 0.967 & 0.934 & 0.924 & 0.2941 & 0.0442 & 95.58 \\
\hline $\mathrm{Sp}=0.248 \mathrm{C}-0.149 \mathrm{PL}+0.220 \% \mathrm{P}_{200}-0.227 \mathrm{w}-16.656$ & 0.850 & 0.723 & 0.679 & 0.6042 & 0.0138 & 98.62 \\
\hline
\end{tabular}




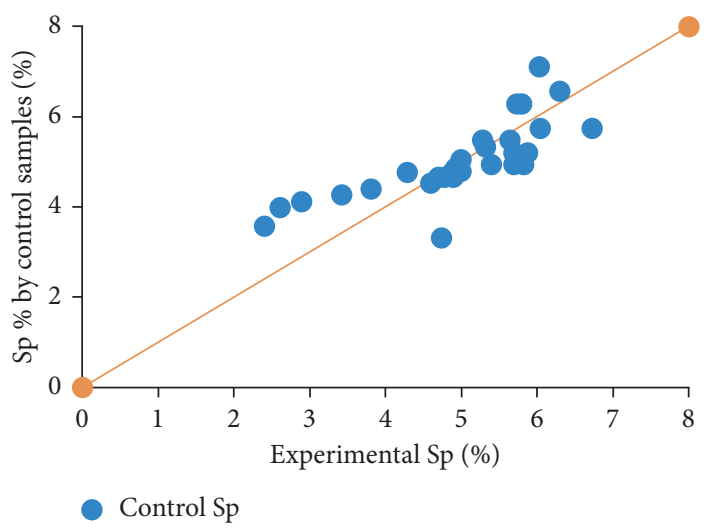

Figure 4: Relationships between experimental and controls Sp.

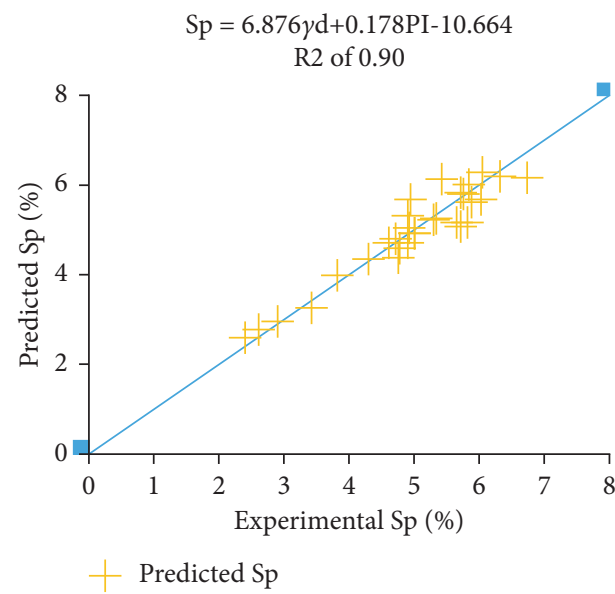

(a)

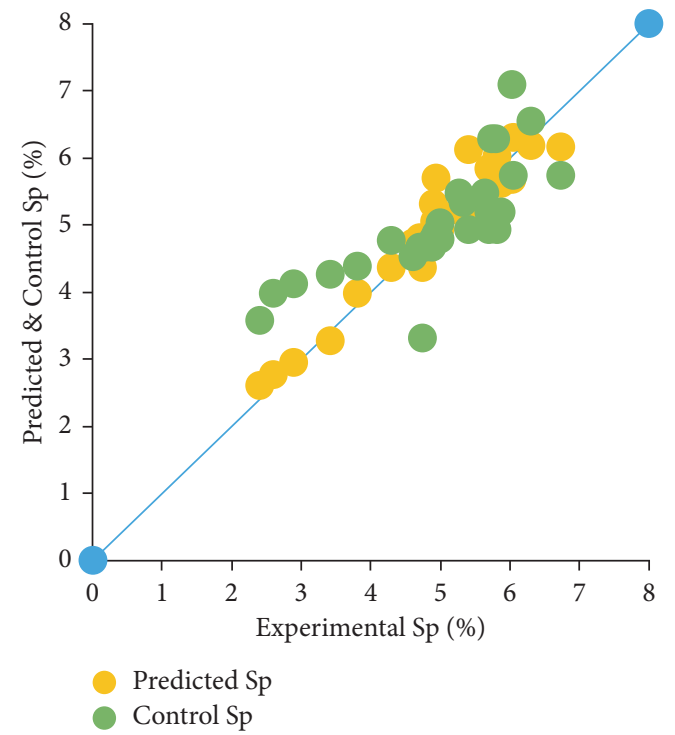

(b)

Figure 5: (a) Relationships between experimental and predicted, (b) variations between control and predicted swelling potential.

the developed analysis is more suitable than compared models thereby variation from the actual swelling potential of the study area [34-36].

\section{Conclusions}

Based on the contemplated investigation and statistical predication of swelling potential of expansive soils using index properties through SPSS statistical regression analysis, the study has drawn the following conclusions:

(i) The soils in the Holte town are expansive that was identified through direct investigations and prediction. As per unified soil classification system, the study area found dominantly by inorganic clays with high plastic clay, $\mathrm{CH}$, and as per AASHTO system it falls under A-7-5 and A-7-6 group that the soils are poor for subgrade construction.

(ii) The laboratory swelling pressure and potential, free swell, and activity results illustrated that the soils are highly expansive thereby the degree of expansiveness presented with high ranges of swelling potential in the study area.

(iii) Based on the multiple regression model, the measurable equation was established to predict swelling potential. The model presented that there is a valid correlation between index properties and swelling potential with higher prediction performance of the soils in the town. The newly developed equation for indirect estimation of swelling potential found was $6.876 \gamma_{d}+0.178 \mathrm{PI}-10.664$ with $R^{2}$ of $90 \%$ and with mean confidence level of $99.99 \%$.

(iv) The obtained test results showed that the increasing plasticity index also significantly increases swelling potential, swelling pressure, and dry density of the soil samples of the study area. The model can be used to characterize and measure the expansiveness of soils for different construction projects in the future specifically in the study area, i.e., Holte town. 


\section{Data Availability}

All the data used in this research were collected from field and tested in Arba Minch Institute of Technology, Civil Engineering Laboratory.

\section{Conflicts of Interest}

The authors declare that there are no conflict of interest.

\section{Acknowledgments}

The authors are thankful to Arba Minch University for providing all laboratory and logistic supports for this research work.

\section{References}

[1] S. A. Ngah and H. O. Nwankwoala, "Evaluation of geotechnical properties of the sub-soil for shallow foundation design in onne, rivers state, Nigeria," International Journal of Engineering Science, vol. 2, no. 11, pp. 8-16, 2013.

[2] A. A. Ayopo and Z. Nalbantoglu, "Lime pile techniques for improvement of clay soils," Canadian Geotechnical Journal, vol. 52, no. 6, pp. 760-768, 2015.

[3] L. C. Lollo, "Geotechnical evaluation of foundation soils for a building (case of a site in jimma city, southwestern Ethiopia)," Journal of Environment and Earth Science, vol. 6, no. 3, pp. 95-98, 2016.

[4] N. K. Ameta, D. G. M. Purohit, and A. S. Wayal, "Characteristics, problems and remedials of expansive soils of Rajasthan, India," Electronic Journal of Geotechnical Engineering, vol. 20, pp. 1-7, 2007.

[5] K. Adugna and Y. Yirga, "“Investigation on engineering characteristics of soils," A case study in wolkite university compound, Ethiopia," Journal of Civil Engineering Research, vol. 10, no. 2, pp. 39-46, 2020.

[6] C. Huang, X. Wang, H. Zhou, and Y. Liang, "Factors affecting the swelling-compression characteristics of clays in yichang, China," Advances in Civil Engineering, vol. 2019, pp. 1-13, 2019.

[7] A. Djedid and N. Ouadah, "Indirect estimation of swelling clay soils parameters," Electronic Journal of Geotechnical Engineering, vol. 18, pp. 661-670, 2013.

[8] I. Gratchev and S. Saeidi, "Free swell of compacted plastic soils," International Journal of Geotechnical Engineering, vol. 14, no. 8, pp. 956-961, 2020.

[9] A. S. Mohammed, "Property correlations and statistical variations in the geotechnical properties of $(\mathrm{CH})$ clay soils," Geotechnical \& Geological Engineering, vol. 36, no. 1, pp. 267-281, 2018.

[10] I. Memarzadeh, A. Lashkari, and P. T. Shourijeh, "Consolidation behavior of structured clayey soils: a case study on shiraz fine alluvial strata," International Journal of Civil Engineering, vol. 16, no. 10, pp. 1435-1444, 2018.

[11] C. Lucian, "Development of models to predict swelling potential based on soil index properties," Journal of Building and Land Development, vol. 14, no. 2, 2007.

[12] Ç. S. Ömür, K. Nilay, and Y. Hüseyin, "Prediction of swelling potential and pressure in compacted clay," Arabian Journal for Science and Engineering, vol. 35, pp. 1535-1546, 2012.

[13] A. K. Mishra, S. Dhawan, and S. M. Rao, "Analysis of swelling and shrinkage behavior of compacted clays," Geotechnical \& Geological Engineering, vol. 26, no. 3, pp. 289-298, 2008.
[14] M. Y. Fattah, N. M. Salim, and E. J. Irshayyid, "Swelling behavior of unsaturated expansive soil," Transportation Infrastructure Geotechnology, vol. 8, no. 1, pp. 37-58, 2021.

[15] M. Y. Fattah, N. M. Salim, and E. J. Irshayyid, "Determination of the soil-water characteristic curve of unsaturated bentonite-sand mixtures," Environmental Earth Sciences, vol. 76, no. 5, 2017.

[16] C. C. Ikeagwuani and D. C. Nwonu, "Emerging trends in expansive soil stabilisation: a review," Journal of Rock Mechanics and Geotechnical Engineering, vol. 11, no. 2, pp. 423-440, 2019.

[17] A. Teklay, M. Haile, A. Teferra, and E. J. Murray, "The effect of sample preparation and testing procedure on the geotechnical properties of tropically weathered residual laterites soils of Ethiopia," Journal of Ethiopian Engineers Association, vol. 33, pp. 45-62, 2015.

[18] A. Sridharan and P. Keshavamurthy, "Expansive soil characterization: an appraisal,” INAEA, vol. 1, pp. 29-33, 2016.

[19] B. Zamin, H. Nasir, K. Mehmood, Q. Iqbal, A. Farooq, and M. Tufail, "An experimental study on the geotechnical, mineralogical, and swelling behavior of KPK expansive soils," Advances in Civil Engineering, vol. 2021, pp. 1-13, 2021.

[20] F. Luo, Q. Luo, and L. W. Jiang, "Influence of variation levels of soil strength indexes on the value of slope stability safety factor," Journal of Civil Architectural \& Environmental Engineering, vol. 37, no. 4, pp. 77-83, 2015.

[21] F. S. Khan, S. Azam, M. E. Raghunandan, and R. Clark, "Compressive strength of compacted clay-sand mixes," Advances in Materials Science and Engineering, vol. 2014, pp. 1-6, 2014.

[22] L. Zhang, F. Dang, J. Gao, and J. Ding, "Measurement and investigation on 1-D consolidation permeability of saturated clay considering consolidation stress ratio and stress history," Geofluids, vol. 2021, pp. 1-21, 2021.

[23] A. Shrestha, A. Jotisankasa, S. Chaiprakaikeow, S. Pramusandi, and S. Nishimura, "Determining shrinkage cracks based on the small-strain shear modulus-suction relationship," Geosciences, vol. 9, no. 9, 2019.

[24] J. James and P. K. Pandian, "Plasticity, swell-shrink, and microstructure of phosphogypsum admixed lime stabilized expansive soil," Advances in Civil Engineering, vol. 2016, pp. 1-10, 2016.

[25] C. Rani, "Predication of swelling pressure of expansive soils using compositional and environmental factors," International Journal of Civil Engineering \& Technology, vol. 4, no. 3, pp. 134-142, 2013.

[26] H. H. Adem and S. K. Vanapalli, "Review of methods for predicting in situ volume change movement of expansive soil over time," Journal of Rock Mechanics and Geotechnical Engineering, vol. 7, no. 1, pp. 73-86, 2015.

[27] C. M. O. Nwaiwu and I. Nuhu, "Evaluation and prediction of the swelling characteristics of Nigerian black clays," Geotechnical \& Geological Engineering, vol. 24, no. 1, pp. 45-56, 2006.

[28] G. Xiang, Y. Xu, F. Yu, Y. Fang, and Y. Wang, "Prediction of swelling characteristics of compacted GMZ bentonite in salt solution incorporating ion-exchange reactions," Clays and Clay Minerals, vol. 67, no. 2, pp. 163-172, 2019.

[29] E. A. Mandhour, "Prediction of compression index of the soil of Al-nasiriya city using simple linear regression model," Geotechnical \& Geological Engineering, vol. 38, no. 5, pp. 4969-4980, 2020.

[30] A. Razmyar and A. Eslami, "Geotechnical characterization of soils in the eastern and western areas of tehran," Engineering, 
Technology \& Applied Science Research, vol. 7, no. 4, pp. 1802-1810, 2017.

[31] C. Chu, M. Zhan, Q. Feng et al., "Effect of drying-wetting cycles on engineering properties of expansive soils modified by industrial wastes," Advances in Materials Science and Engineering, vol. 2020, pp. 1-9, 2020.

[32] Y. B. Yamusa, R. Sa'ari, K. Ahmad, N. Alias, M. Mustaffar, and L. K. Foong, "Monitoring leachate migration in compacted soil using digital image technique," Engineering, Technology \& Applied Science Research, vol. 9, no. 1, pp. 3685-3691, 2019.

[33] D. A. Sun, L. Zhang, J. Li, and B. Zhang, "Evaluation and prediction of the swelling pressures of GMZ bentonites saturated with saline solution," Applied Clay Science, vol. 105106, pp. 207-216, 2015.

[34] F. H. Chen, Foundation on Expansive Soils, Elsevier Scientific Publishing Company Inc., New York, America, 2012.

[35] H. B. Seed, R. J. Woodward, and R. Lundgren, "Prediction of swelling potential for compacted clays," Journal of ASCE, vol. 88 , no. $3,1962$.

[36] J. S. L'Heureux and T. Lunne, “Characterization and engineering properties of natural soils used for geotesting," AIMS Geosci, vol. 6, pp. 35-53, 2020. 